\title{
Treponema pallidum promotes macrophage polarization and activates the NLRP3 inflammasome pathway to induce interleukin-1 $\beta$ production
}

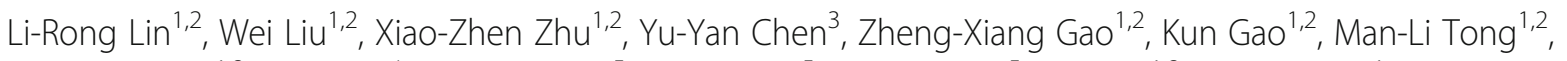 \\ Hui-Lin Zhang ${ }^{1,2}$, Yao Xiao ${ }^{4}$, Wen-Dong Li ${ }^{5}$, Shu-Lian Li ${ }^{5}$, Hui-Ling Lin' ${ }^{5}$ Li-Li Liu ${ }^{1,2}$, Zan-Xi Fang ${ }^{1}$, Jian-Jun Niu ${ }^{1,2^{*}}$, \\ Yong Lin ${ }^{1,2^{*}}$ and Tian-Ci Yang ${ }^{1,2^{*}}$ (D)
}

\begin{abstract}
Background: The involvement of inflammasome activation and macrophage polarization during the process of syphilis infection remains unknown. In this study, A series of experiments were performed using human macrophages to research the role of NLRP3 inflammasome regulation in interleukin (IL)-1 $\beta$ production and its influence on macrophage polarization triggered by T. pallidum.

Results: The results showed that in M0 macrophages treated with T. pallidum, the M1-associated markers inducible nitric oxide synthase (iNOS), IL-1 $\beta$ and TNF-a were upregulated, and the M2-associated markers CD206 and IL-10 were downregulated. In addition, we observed NLRP3 inflammasome activation and IL-1 $\beta$ secretion in T. pallidum-treated macrophages, and the observed production of IL-1 $\beta$ occurred in a dose- and time-dependent manner. Moreover, the secretion of IL-1 $\beta$ by macrophages after T. pallidum treatment was notably reduced by anti-NLRP3 siRNA and caspase-1 inhibitor treatment. NAC, $\mathrm{KCl}$, and CA074-ME treatment also suppressed IL-1 $\beta$ release from T. pallidum-treated macrophages.

Conclusions: These findings showed that T. pallidum induces MO macrophages to undergo M1 macrophage polarization and elevate IL-1 $\beta$ secretion through NLRP3. Moreover, the process of NLRP3 inflammasome activation and IL-1 $\beta$ production in macrophages in response to T. pallidum infection involves $\mathrm{K}^{+}$efflux, mitochondrial ROS production and cathepsin release. This study provides a new insight into the innate immune response to T. pallidum infection.
\end{abstract}

Keywords: Treponema pallidum, Macrophage, Polarization, NLRP3, IL-1 $\beta$

\section{Background}

Syphilis is an infectious, sexually transmitted disease resulting from infection by Treponema pallidum [1, 2]. Develop lesions in compromised tissues of infected patients are a direct manifestation of the inflammatory processes triggered by T. pallidum [2-4]. T.pallidum' pathogen-associated molecular patterns are recognized by the host immune system

\footnotetext{
* Correspondence: niujianjun211@xmu.edu.cn; mikhail929@163.com; yangtianci@xmu.edu.cn

${ }^{1}$ Zhongshan Hospital, Medical College of Xiamen University, Xiamen, Fujian Province, China

Full list of author information is available at the end of the article
}

through pattern recognition receptors expressed by macrophages or dendritic cells, including intracellular receptors and membrane-bound [4-6]. This recognition of pathogen-associated molecular patterns activates various members of the nucleotide-binding leucine-rich receptor (NLR) family in the cytoplasm, which results in the assembly of an NLR-containing multiprotein complex that recruits and activates caspase- 1 and thereby in the production of proinflammatory cytokines, including interleukin (IL)-1 $\beta$, IL-18 and IL-33. In addition, IL-1 $\beta$ is an inflammatory marker that is commonly used to reflect activation of the NLRP3 inflammasome [7-9].

(c) The Author(s). 2018 Open Access This article is distributed under the terms of the Creative Commons Attribution 4.0 International License (http://creativecommons.org/licenses/by/4.0/), which permits unrestricted use, distribution, and 
NLRP3, the most well-studied Nod-like receptor, forms a complex composed of adaptor proteins, such as apoptosis-associated speck-like protein, and the serine protease caspase- $1[4,10]$. The NLRP3 inflammasome is activated by a broad range of stimuli arising from pathogen-associated molecular patterns released during viral, bacterial, fungal, or protozoal infection [11-14]. Previous research has revealed that NLRP3 inflammasome activation induces cathepsin $\mathrm{B}$ release, potassium $\left(\mathrm{K}^{+}\right)$efflux, and reactive oxygen species (ROS) generation [15]. $T$. pallidum infection is capable of inducing IL- $1 \beta$ production in Kupffer cells, and the purified T. pallidum lipoproteins TpF1, TpN47, TmpA, and TpN15-TpN17 are associated with the induction of tumor necrosis factor $\alpha$ $(\mathrm{TNF}-\alpha)[16,17]$. Our previous study have found that the proinflammatory cytokine IL- $1 \beta$ is mainly secreted accompanied by NLRP3 inflammasome activation in the T.pallidum infected rabbits [4]. However, the involvement of inflammasome activation in macrophages during the process of syphilis infection remains unknown.
In the present study, A series of experiments were performed employing macrophages derived from human monocytic cell line (THP-1) to investigate the role of NLRP3 inflammasome regulation in IL-1 $\beta$ production and the influence of the NLRP3 inflammasome on macrophage polarization triggered by T. pallidum.

\section{Results}

\section{T. pallidum promotes macrophage polarization}

THP-1 cells treated with PMA for $48 \mathrm{~h}$ exhibited a lack of proliferation, became attached and spread, and differentiated to M0 macrophages. The M0 macrophages were incubated with T. pallidum at a multiplicity of infection (MOI) of 20:1 for $12 \mathrm{~h}$, and the morphology of the cells changed from suborbicular (Fig. 1a) to long fusiform with long pseudopodia, as observed by fluorescence microscopy (Fig. 1b). Macrophages treated with T. pallidum for $12 \mathrm{~h}$ showed notably increased mRNA levels of IL-1 $\beta$, TNF- $\alpha$ and inducible nitric oxide synthase (iNOS) but decreased mRNA levels of IL-10 and CD206 compared with the levels observed in the PBS-treated control
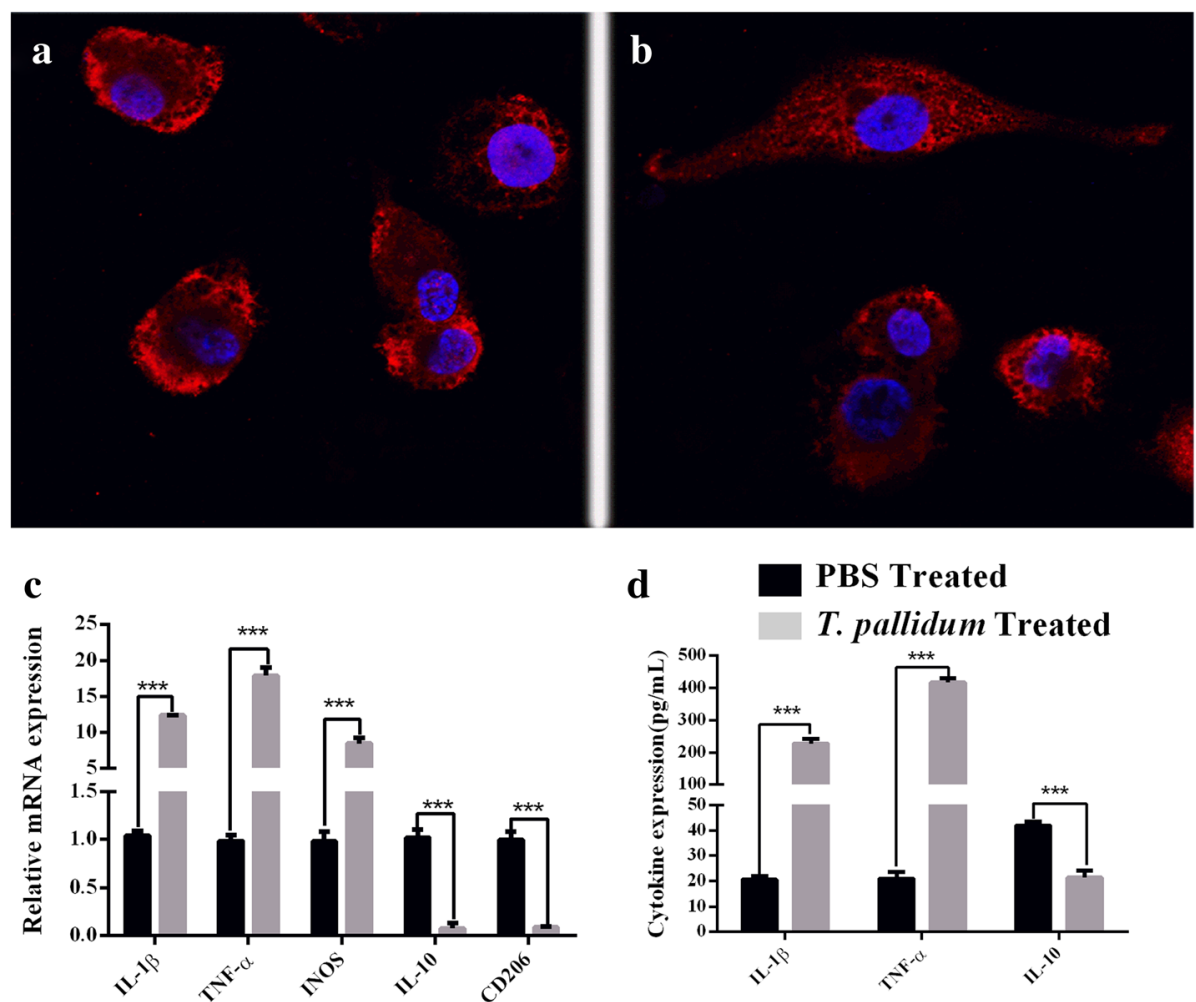

Fig. 1 T. pallidum promotes macrophage polarization. a, THP-1 cells differentiated to M0 macrophages, and the morphological changes were observed by confocal microscopy (1000x). Nuclei were stained with DAPI (blue), and actin was stained with Alexa Fluor 633 phalloidin (red). Confocal laser scanning microscopy was conducted using an LSM700 confocal microscope (Zeiss, Oberkochen, Germany). b, Morphological changes in the macrophages treated with T. pallidum for $12 \mathrm{~h}(1000 \times)$. The image shows the typical morphological changes in the macrophages. The percentage of long orbicular macrophage cells among the macrophages after T. pallidum infection for $12 \mathrm{~h}$ was approximately $60 \%$ (data not shown). c, Cytokine mRNA levels in M0 macrophages treated with T. pallidum for 12 h. d, Cytokine protein levels in M0 macrophages treated with T. pallidum for $12 \mathrm{~h}$. The results shown are from one experiment that is representative of three independent experiments and are expressed as the means \pm SDs. Student's t-test was applied to compare the means between two groups. ${ }^{* *} P<0.001$ 
group $(p<0.001)$ (Fig. 1c). In addition, the macrophages treated with $T$. pallidum expressed significantly higher TNF- $\alpha$ and IL-1 $\beta$ protein levels but lower IL-10 levels than the PBS-treated group $(P<0.001)$ (Fig. 1d).

\section{T. pallidum promotes NLRP3 inflammasome activation and IL-1 $\beta$ expression in macrophages}

The mRNA levels of NLRP3, caspase- 1 , and IL-1 $\beta$ in M0 macrophages treated with $T$. pallidum at various MOIs (20:1, 50:1, 100:1 and 200:1) for $12 \mathrm{~h}$ increased in a dose-dependent manner $(P<0.001)$ (Fig. 2a-c). Stimulation with $T$. pallidum also induced IL-1 $\beta$ protein production by the macrophages in a dose-dependent manner (Fig. 2d). In contrast, a statistical analysis showed that the NLRP3 and active caspase-1 protein levels in the treated cells were significantly higher than those in the control group, but significantly different levels were not obtained with the various MOIs (Fig. 2e, f). In addition, macrophages incubated with T. pallidum at an MOI of 20:1 for 0, 2, $4,6,8$, and $12 \mathrm{~h}$ showed increases in the mRNA levels of NLRP3, caspase-1, and IL-1 $\beta$ and in the concentration of IL-1 $\beta$ over time (Fig. 3a-d). In addition, the concentrations of NLRP3, active-caspase-1 and IL-1 $\beta$ increased with increases in the incubation time (Fig. 3e, f).

\section{Impact of NLRP3-targeting siRNA on IL-1 $\beta$ expression}

To further investigate the effect of the treatment of macrophages with $T$. pallidum on IL- $1 \beta$ expression and release, NLRP3 was knocked down in macrophages with anti-NLRP3 siRNA. The results showed that $12 \mathrm{~h}$ after transfection, the anti-NLRP3 siRNA group exhibited significantly $(P<0.001)$ decreased mRNA levels of NLRP3, caspase-1, and IL-1 $\beta$ (Fig. 4) and significantly $(P<0.001)$ reduced secretion of IL-1 $\beta$. The mRNA or protein levels of NLRP3, IL-1 $\beta$, and caspase-1 in the blank group were set to $100 \%$. After siRNA transfection, the mRNA levels of NLRP3, caspase- 1 and IL- $1 \beta$ were inhibited by approximately $57 \%, 62 \%$ and $41 \%$, respectively, compared with those in the blank group, whereas the IL-1 $\beta$ protein levels were inhibited by 33\% (Fig. 4a). Furthermore, a western blotting analysis revealed that the protein levels of NLRP3, active-caspase- 1 and IL-1 $\beta$ were significantly reduced in the anti-NLRP3 siRNA group (Fig. 4b, c). The above-described mRNA or protein levels were not significantly different between the blank group and the negative group.

\section{Inhibition of cathepsin B, ROS, K+ and caspase-1 impairs NLRP3 inflammasome activation and IL-1 $\beta$ expression in T. pallidum-infected macrophages}

The analysis of M0 macrophages pretreated with four inhibitors showed that the expression of NLRP3 in the
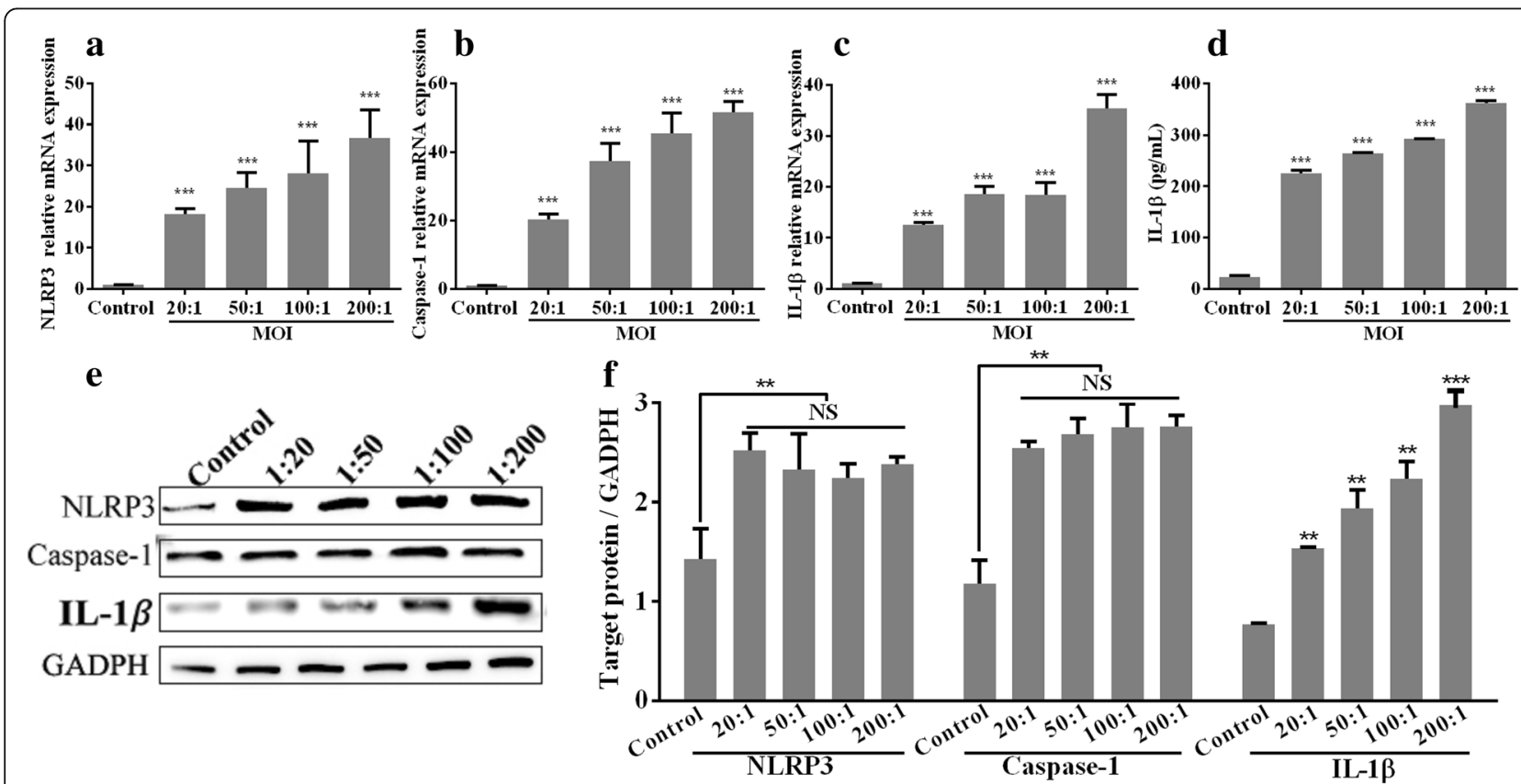

Fig. 2 T. pallidum (at different MOIs) promotes NLRP3 inflammasome activation and IL-1 $\beta$ expression in macrophages. $\mathbf{a}$, mRNA levels of NLRP3. $\mathbf{b}$, mRNA levels of caspase-1. c, mRNA levels of IL-1 $\beta$. d, Protein levels of IL-1 $\beta$. e and $\mathbf{f}$, Protein levels of NLRP3, active caspase-1, and IL-1 $\beta$ determined through a western blotting analysis. MO macrophages treated with PBS served as the control group. The values represent the means \pm SDs of triplicate trials and are representative of three independent experiments. The western blotting results are representative of three independent experiments. Student's t-test was used to compare the different $\mathrm{MOI}$ treatments with the control group. ${ }^{* *} P<0.01$; ${ }^{* *} P<0.001$ 


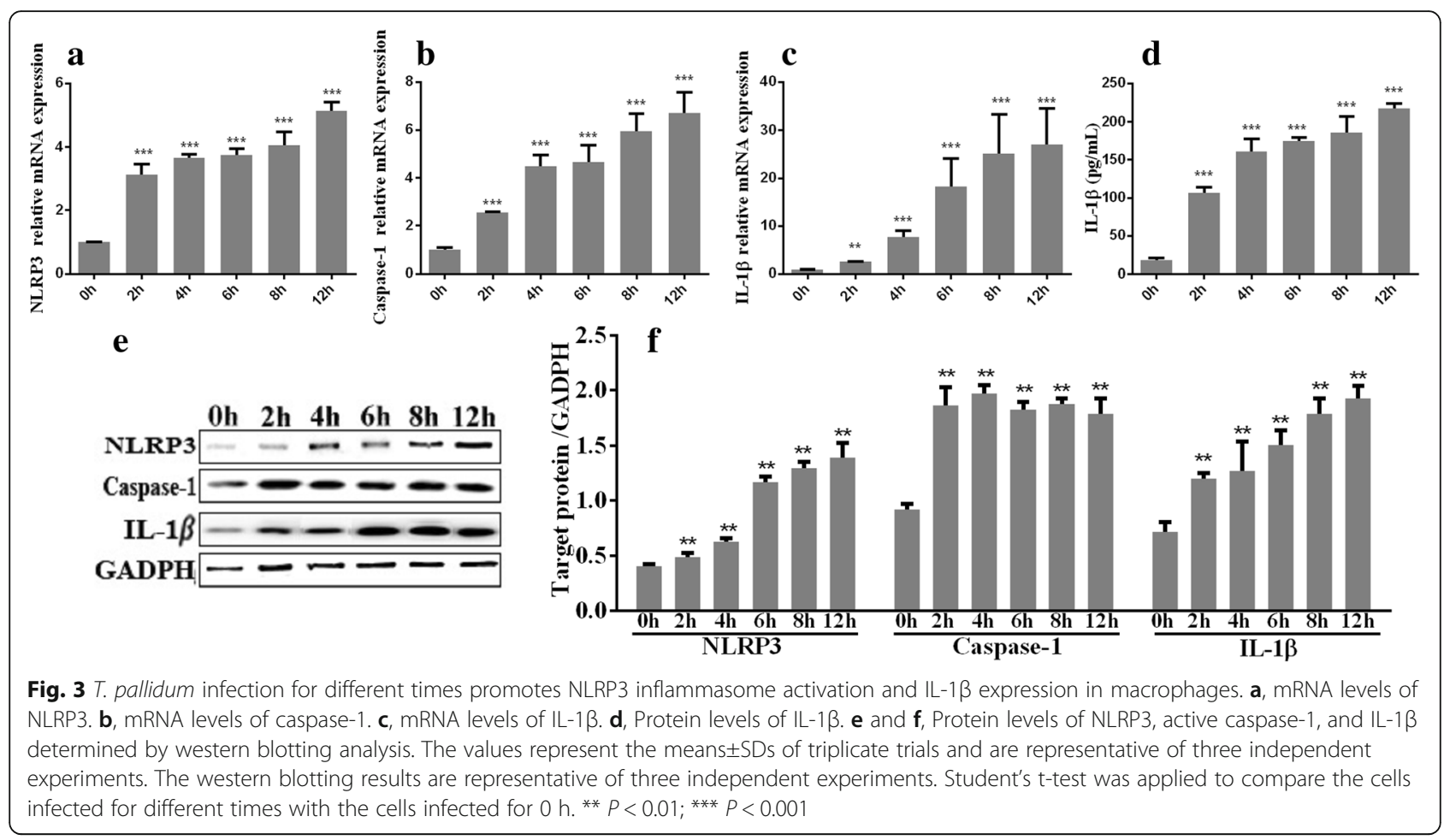

macrophages treated with $T$. pallidum for $12 \mathrm{~h}$ was significantly inhibited by the $\mathrm{KCl}$ and CA074-ME pretreatments but not by the NAC and Z-VAD-FMK pretreatments (Fig. 5a), and the expression of caspase- 1 mRNA was significantly inhibited by all four inhibitors, particularly CA074-ME and Z-VAD-FMK (Fig. 5b). In addition, $\mathrm{KCl}$, CA074-ME and Z-VAD-FMK inhibited IL-1 $\beta$ at both the mRNA and protein levels, whereas NAC inhibited IL-1 $\beta$ at the protein level but not the mRNA level (Fig. 5c, d). Furthermore, all four inhibitors suppressed the IL- $1 \beta$ protein levels but had no effect on the NLRP3 and active-caspase-1 protein levels, as demonstrated in a western blotting analysis (Fig. 5e, f).

\section{Discussion}

In our previous study, we have found that the early inflammatory response to T. pallidum infection is most often attributed to the local innate and adaptive cellular immune responses [3, 4]. Macrophages are the major cells in the innate immune response and play a crucial role in the early inflammatory reaction. The crucial role of macrophages in the pathogeny of syphilis was initially confirmed through a histological analysis of tissues from T. pallidum-infected rabbits $[4,18,19]$, and subsequently, the immune sera from $T$. pallidum-infected rabbits showed markedly enhanced spirochetal clearance by peritoneal macrophages in vitro, supporting the previously described assumption [20]. The results of previous studies are generally consistent with those obtained in the rabbit model [4], and a large number of macrophages was observed in early syphilis lesions [20]. The mechanism underlying the involvement of macrophages in the early inflammatory response remains elusive. The results of our in vitro study showed that T. pallidum induced the polarization of M0 macrophages into M1 macrophages at the early infection phase. Within $12 \mathrm{~h}$ of infection, the expression of iNOS, an M1 surface marker, was upregulated, and the expression of CD206, an M2 surface marker, was decreased, which was similar with our previous study [3]. Moreover, the mRNA and protein expression levels of the M1-associated cytokines IL-1 $\beta$ and TNF- $\alpha$ and of the M2-associated cytokine IL-10 were elevated and reduced, respectively. In addition, we found that macrophages responded to $T$. pallidum infection, and this response was also accompanied by NLRP3 inflammasome activation and IL-1 $\beta$ secretion in vitro study.

Several types of NLRs are involved in inflammasome activation, and the NLRP3 inflammasome has been the most extensively studied of these NLRs [21]. Babolin et al. reported that TpF1 from T. pallidum triggers the synthesis of pro-IL-1 $\beta$ and inflammasome activation in monocytes, resulting in the release of IL-1 $\beta$ [17]. In the T. pallidum-infected rabbits, we found that proinflammatory cytokine IL- $1 \beta$ is mainly secreted accompanied by NLRP3 inflammasome activation [4]. In the present study, we confirmed that T. pallidum infection activated the NLRP3 inflammasome and induced IL-1 $\beta$ secretion 


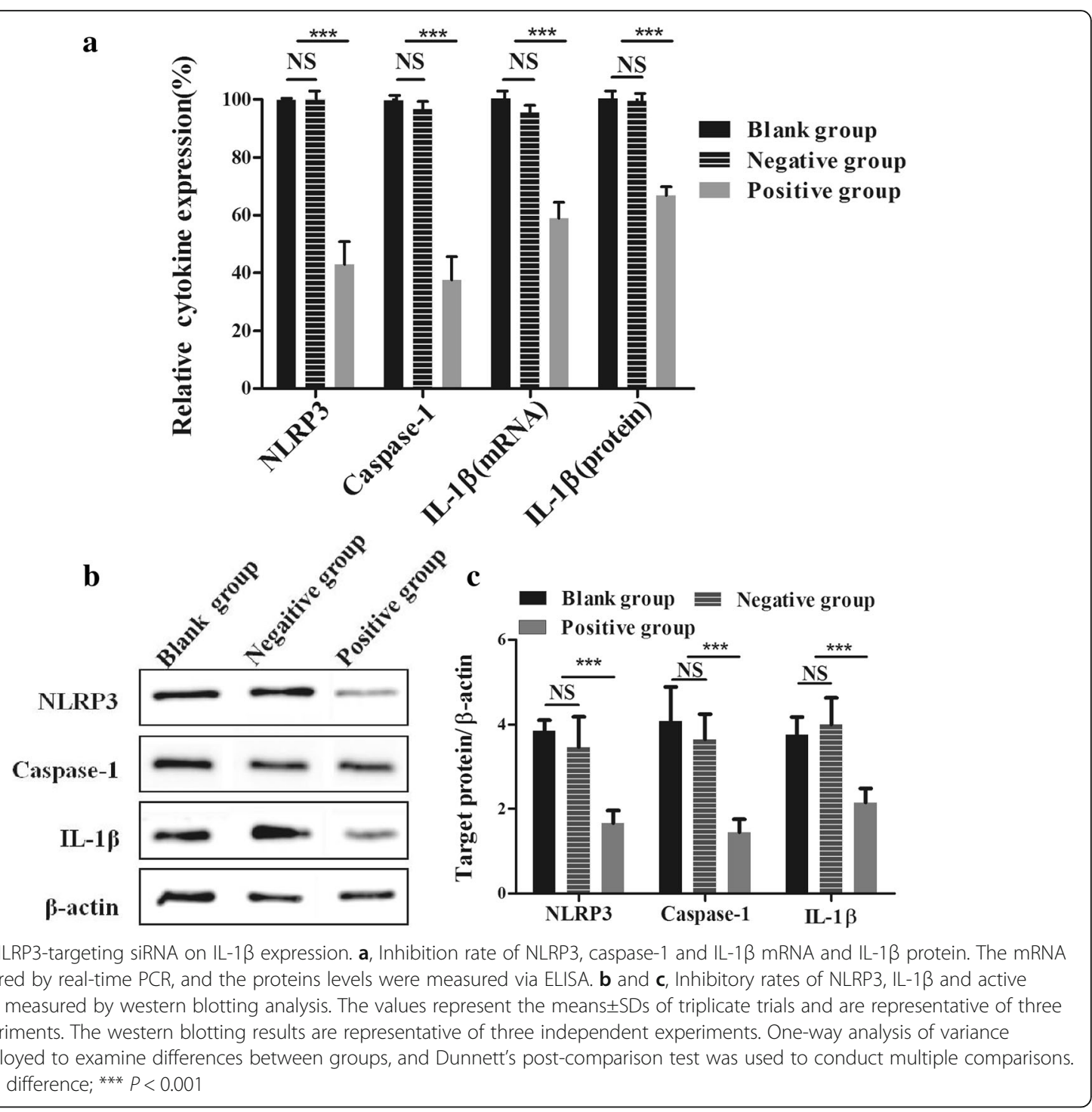

in macrophages in a dose- and time-dependent manner in vitro study. The NLRP3 inflammasome, which is essential for IL- $1 \beta$ processing and secretion from macrophages, mediates IL-1 $\beta$ production in immune cells in response to T. pallidum. In addition, caspase- 1 -mediated cleavage is the limiting step in the processing of IL- $1 \beta$ into its secreted active forms [22]. Moreover, the knockdown of the NLRP3 gene by anti-NLRP3 siRNA and the inhibition of caspase-1 activation directly led to decreased expression of IL-1 $\beta$ in T. pallidum-induced macrophages. These findings suggest that T. pallidum activates the NLRP3 inflammasome in macrophages to induce IL-1 $\beta$ production in vitro study..

Several cellular events, including cathepsin release from damaged lysosomes, mitochondrial ROS generation and $\mathrm{K}^{+}$efflux, have been proposed as underlying mechanisms associated with activation of the NLRP3 inflammasome [23-25]. After NLRP3 activation, caspase-1 induces IL-1 $\beta$ processing and secretion [5]. In the present study, M0 macrophages were pretreated with three different inhibitors and then co-cultured with T. pallidum to observe whether the observed effects of T. pallidum on caspase-1 expression and IL- $1 \beta$ production are inhibited by signaling inhibitors. Caspase- 1 activation in the macrophages was markedly inhibited by treatment with three inhibitors, namely, $\mathrm{KCl}$ (a potassium channel inhibitor), NAC (an ROS inhibitor), and CA074-ME (a cathepsin B inhibitor). The production of IL-1 $\beta$ by the macrophages was also notably inhibited. These results confirmed that key signals, including $\mathrm{K}^{+}$efflux, mitochondrial ROS generation and cathepsin release, are involved in NLRP3 inflammasome activation and IL- $1 \beta$ production in macrophages in response to $T$. pallidum infection.

In this study, we verified the role of NLRP3 inflammasome regulation in IL-1 $\beta$ production triggered by $T$. palli$d u m$ in vitro. Further studies are required to understand 


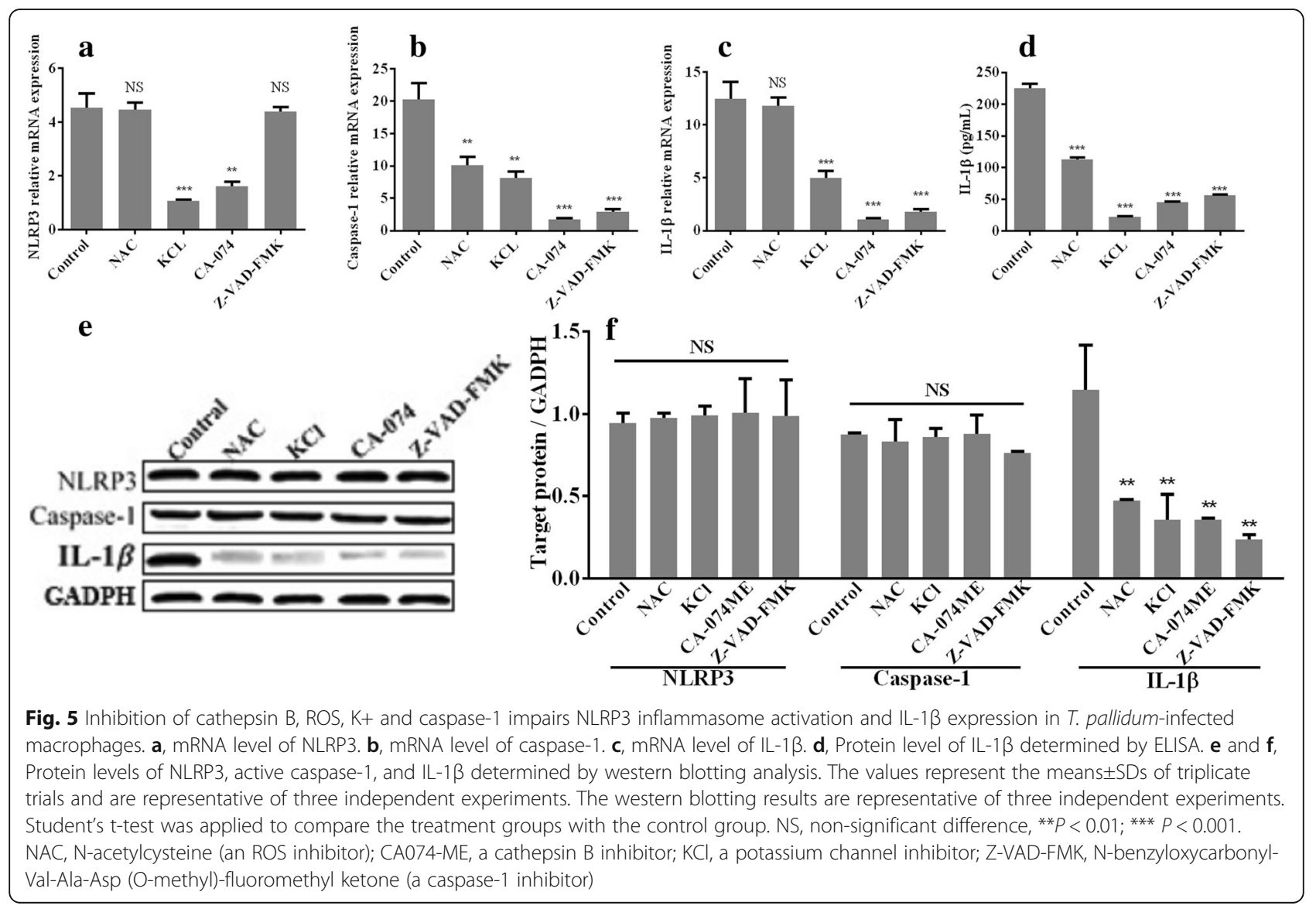

the roles of NLRP3 inflammasome regulation and IL-1 $\beta$ in T. pallidum-infected animals. In addition, although the NLRP3 inflammasome was knocked down by siRNA, all the experiments involved pharmacologic agents with inherent specificity limitations. Future studies with NLRP3and caspase-1-knockout cell lines would provide more direct information concerning the roles of these factors in T. pallidum infection.

\section{Conclusions}

In summary, our results show that $T$. pallidum induces macrophages to undergo M1 macrophage polarization and elevates IL-1 $\beta$ secretion through NLRP3 activation in macrophages. In addition, various signals, including ROS production, $\mathrm{K}^{+}$efflux and cathepsin $\mathrm{B}$ release, might be involved in IL-1 $\beta$ production and NLRP3 inflammasome activation. Our study provides a new insight into the innate immune response to $T$. pallidum infection.

\section{Methods}

\section{Preparation of macrophages}

As described in our previous studies [3], THP-1 cells were obtained from the American Type Culture Collection (ATCC, Manassas, VA, USA). The cells were incubated in RPMI 1640 medium (HyClone, Logan, UT, USA) with $10 \%(v / \mathrm{v})$ heat-inactivated fetal bovine serum (Biological Industries Ltd., Kibbutz Beit Haemek, Israel), $100 \mathrm{U} / \mathrm{mL}$ penicillin and $100 \mathrm{~g} / \mathrm{mL}$ streptomycin (Invitrogen/Life Technologies, Carlsbad, CA, USA). The cells were incubated in a humidified $5 \% \mathrm{CO}_{2}$ atmosphere at $37{ }^{\circ} \mathrm{C}$, and $5 \mathrm{ng} / \mathrm{mL}$ phorbol 12-myristate 13-acetate (PMA; Sigma-Aldrich, St. Louis, MO, USA) was then added to induce THP-1 cell differentiation into M0 macrophages for the subsequent experiments. The cytotoxicity assay was performed using an LDH kit according to the manufacturer's instructions (Cayman Chemical Co, MI, USA).

\section{Effect of $T$. pallidum on macrophage polarization}

The T. pallidum Nichols strain was kindly provided by Lorenzo Giacani, PhD (University of Washington, Seattle, WA, USA) and was propagated in rabbits as previously described [1]. Macrophages were cultured with T. pallidum as our previous described [3]. Briefly, macrophages were cultured with $T$. pallidum at an MOI (treponema:cell) of 20:1 for $12 \mathrm{~h}$. Following treatment, cell lysates were collected for assessment of the mRNA expression of IL-1 $\beta$, TNF- $\alpha$, iNOS, IL-10, and CD206 by real-time PCR using the primers are listed in Table 1 . The threshold cycle (Ct) of the target product was normalized to that of the 
Table 1 Primers used for real-time PCR in this study

\begin{tabular}{ll}
\hline Genes & Primers $\left(5^{\prime} \rightarrow 3^{\prime}\right)$ \\
\hline NLRP3 & Forward AACAGCCACCTCACTTCCAG \\
& Reverse CCAACCACAATCTCCGAATG \\
Caspase-1 & Forward GCACAAGACCTCTGACAGCA \\
& Reverse TTGGGAGTTCTTGTATTC \\
IL-1ß & Forward GATGGCTTATTACAGTGGC \\
& Reverse CCTTGCTGTAGTGGTGGT \\
GADPH & Forward GAAGGTGAAGGTCGGAGTC \\
iNOS & Reverse GAAGATGGTGATGGGATTC \\
& Forward CAGCATCCACGCCAAGAA \\
TNF-a & Reverse CAGGTGTTCCCCAGGTAGGTAG \\
& Forward ATGAGCACTGAAAGCATGAT \\
CD206 & Reverse GGGCTGATTAGAGAGAGGTC \\
& Forward GATACCTGCGACAGTAAACGA \\
IL-10 & Reverse CTGGCTATAAGGGATTGTGAAG \\
& Forward GGGTAAGCCATAAGCGAATC \\
& Reverse GGGCAACAAGAGCGAAACT \\
\hline
\end{tabular}

internal standard glyceraldehyde 3-phosphate dehydrogenase (GADPH). The concentrations of IL- $1 \beta$, TNF-a, and IL-10 in cell culture supernatants were detected using commercial ELISA kits according to the manufacturer's recommended protocols (eBiosciences, San Diego, CA, USA). Macrophages treated with PBS were employed as the control group.

\section{NLRP3 activation and IL-1 $\beta$ expression in macrophages infected with $T$. pallidum}

M0 macrophages $\left(5 \times 10^{5}\right.$ cells $/ \mathrm{ml} /$ well $)$ in $2 \mathrm{~mL}$ of RPMI 1640 medium were cultured with T. pallidum at various MOIs (20:1, 50:1, 100:1 and 200:1) for $12 \mathrm{~h}$, and macrophages treated with PBS were set as the control group. In addition, $T$. pallidum $\left(1 \times 10^{7}\right.$ treponema $/ \mathrm{mL} /$ well $)$ was co-cultured with M0 macrophages $\left(5 \times 10^{5}\right.$ cells $/ \mathrm{mL} /$ well $)$ for $0,2,4,6,8$ and $12 \mathrm{~h}$ at $37{ }^{\circ} \mathrm{C}$ in a $5 \% \mathrm{CO}_{2}$ incubator. Following the treatments, cell lysates were collected for the examination of mRNA and protein expression, and cell culture supernatants were used for cytokine measurements.

\section{NLRP3 and IL-1 $\beta$ mRNA expression analysis}

For the assessment of mRNA expression, the total RNA from the above-described cultured cells was isolated using an RNeasy kit (Qiagen Inc., Valencia, CA, USA) and reverse transcribed with a high-capacity cDNA reverse-transcription kit (Applied Biosystems, USA). The primer pairs used for NLRP3, caspase-1, IL-1 $\beta$ and GADPH are listed in Table 1. The generated cDNA was amplified via quantitative PCR using TaqMan gene expression assays (Applied Biosystems, USA) with a 7500 real-time PCR system (Applied Biosystems, USA). The
Ct of the target product was normalized to that of GADPH.

\section{NLRP3 and IL-1 $\beta$ protein expression analysis}

The above-described cultured cells were also disrupted in $1 \%$ Nonidet P-40 lysis buffer [50 mM Tris- $\mathrm{HCl}$ (pH 7.4), $150 \mathrm{mM} \mathrm{NaCl}, 1 \%$ Nonidet P-40 ( $/ \mathrm{v}), 2 \mathrm{mM}$ EDTA, and $2 \mathrm{mM}$ DTT with protease inhibitors; Roche Applied Science, USA], and the concentration of the extracted proteins was measured using a BCA protein assay kit (Takara Inc., Dalian, China). The samples were separated on $10 \%$ SDS-PAGE gels and then transferred to an Immun-Blot PVDF membrane for $1 \mathrm{~h}$ at $4{ }^{\circ} \mathrm{C}$ and $400 \mathrm{~mA}$. After blocking with $5 \%$ milk and TBST, the membranes were incubated overnight at $4{ }^{\circ} \mathrm{C}$ with the following primary antibodies: anti-IL-1 $\beta$ (1:2000 dilution; Origene Inc., USA), anti-NLRP3 (1:1000 dilution; Abcam Inc., USA), anti-caspase-1 (active caspase-1(P20), 1:2000 dilution; R\&D Systems Inc., USA) or anti- $\beta$-actin (1:5000 dilution; Abcam Inc., USA). The membranes were then incubated with the secondary antibody (1:5000 dilution) for $1 \mathrm{~h}$, and the signals were detected using by enhanced chemiluminescence (ECL kit, Millipore Inc., USA). The IL-1 $\beta$ level in cell culture supernatants were also measured by ELISA as previously described.

\section{Impact of NLRP3-targeting siRNA on IL-1 $\beta$ expression}

The transfection mixture comprised $3 \mu \mathrm{L}$ of Lipofectamine 2000 (Invitrogen Inc., USA) and $50 \mathrm{nM}$ anti-NLRP3 siRNA (5'-GGTGTTGGAATTAGACAAC-3'; 5'-GGATCAAAC TACTCTGTGA-3'; 5'-GGAGAGACCTTTATGAGAA-3') in $500 \mu \mathrm{L}$ of Opti-MEM (Ribo, GuangDong, China). The transfection mixture was incubated for $15 \mathrm{~min}$ prior to its addition to M0 macrophages. The transfected macrophages were then co-cultured with the T. pallidum Nichols strain $\left(1 \times 10^{7}\right.$ treponema/mL/well) for $4 \mathrm{~h}$, and after the addition of antibiotic-free growth medium, the culture was further incubated for $12 \mathrm{~h}$. Following the treatments, cell lysates were collected for assessments of mRNA and protein expression, and cell culture supernatants were used for ELISA as described above. PBS solution (pH 8.0, 0.1 M) was used as the blank control, and cells transfected with a non-targeted control siRNA (50 nM) were used as the negative control.

Inhibitory effects of cathepsin B, ROS, $\mathrm{K}^{+}$, and caspase-1 and their impact on IL-1 $\beta$ expression

M0 macrophages were preincubated for $30 \mathrm{~min}$ with various inhibitors, namely, $25 \mathrm{mM} \mathrm{N}$-acetylcysteine (NAC) (a ROS inhibitor; Sigma-Aldrich, St. Louis, MO, USA), 30 mM CA074-Me (a cathepsin B inhibitor; Calbiochem, San Diego, CA, USA), $100 \mathrm{mM} \mathrm{KCl} \mathrm{(a} \mathrm{potassium} \mathrm{channel}$ inhibitor; Sigma, St. Louis, MO, USA), or $2 \mu \mathrm{M} N$-benzyloxycarbonyl-Val-Ala-Asp(O-methyl)-fluoromethyl ketone 
(Z-VAD-FMK; a caspase-1 inhibitor; Invitrogen Inc., USA). The macrophages were then co-cultured with $T$. pallidum for $12 \mathrm{~h}$ as described above. Following the treatments, cell lysates were collected for the assessment of RNA and protein expression, and cell culture supernatants were used for ELISA as described above. M0 macrophages treated with T. pallidum but not preincubated with the inhibitors were employed as the control group.

\section{Statistical analysis}

Student's t-test was applied to compare the means between two groups. One-way analysis of variance (ANOVA) were used to evaluate statistically significant differences among more than two groups, and Dunnett's post-comparison test was used to conduct multiple comparisons. A two-tailed $p$ value less than 0.05 was accepted to indicate statistical significance. All the statistical analyses were performed using Prism software (version 5.0, GraphPad Software Inc., San Diego, CA, USA).

\section{Abbreviations}

IL-1 $\beta$ : interleukin-1 $\beta$; NLRP3: nucleotide-binding leucine-rich receptor protein 3; ROS: reactive oxygen species

\section{Acknowledgments}

We acknowledge all our colleagues at the Institute of Infectious Disease, Medical College of Xiamen University, for supporting this project.

\section{Funding}

This work was supported by the National Natural Science Foundation [grant numbers 81772260, 81672094, 81771312, 81471967, 81471231, 81401749, $81301501,81201360,81271335$, and 81171625], the National Science Foundation for Distinguished Young Scholars of Fujian [grant number 2014D001], the Youth Foundation Project of Fujian Provincial Health Department [grant numbers 2017-2-105 and 2017-2-113], the Major Special Projects of Serious IIIness in Xiamen [grant numbers 3502Z20179045], the Natural Science Foundation of Fujian Province [grant numbers 2018D0014, $2016 \mathrm{~J} 01626$ and 2015 J01540] and the Medical Innovation Project of Fujian Health Development Planning Commission [grant numbers 2012-CXB-34]. The funding sources had no role in the study design, data collection or analyses, the decision to publish, or the preparation of this manuscript.

\section{Availability of data and materials}

All data generated or analyzed in the current study are available from the corresponding author upon reasonable request.

\section{Authors' contributions}

$J J N, Y L$ and TCY conceived and designed the study. LRL, WL, and XZZ analyzed the data and drafted the manuscript. YYC, ZXG, and KG contributed to analysis and interpretation data. MLT, HLZ, YX, WDL, SLL, HLL, LLL and ZXF collected the samples and acquired data. LRL, TCY, LLL, MLT, ZXF, YYC, YX, $J J \mathrm{~N}$ and HLZ obtained the funding and revised the manuscript critically for important intellectual content. All the authors read and approved the final manuscript.

\section{Ethics approval}

This study was approved by the animal experimental ethics committee of the Medical College of Xiamen University.

\section{Consent for publication}

Not applicable.

\section{Competing interests}

The authors declare that they have no competing interests.

\section{Publisher's Note}

Springer Nature remains neutral with regard to jurisdictional claims in published maps and institutional affiliations.

\section{Author details}

'Zhongshan Hospital, Medical College of Xiamen University, Xiamen, Fujian Province, China. ${ }^{2}$ Institute of Infectious Disease, Medical College of Xiamen University, Xiamen, Fujian Province, China. ${ }^{3}$ Xiamen Fifth Hospital, Xiamen, Fujian Province, China. ${ }^{4}$ Xiamen Hospital of Traditional Chinese Medicine, Xiamen, Fujian Province, China. ${ }^{5}$ Xiamen Huli District Maternity and Child Care Hospital, Xiamen, Fujian Province, China.

Received: 2 May 2018 Accepted: 16 August 2018

Published online: 14 September 2018

\section{References}

1. Tong ML, Zhao Q, Liu LL, Zhu XZ, Gao K, Zhang HL, Lin LR, Niu JJ, Ji $Z \mathrm{~L}$, Yang TC. Whole genome sequence of the Treponema pallidum subsp. pallidum strain Amoy: an Asian isolate highly similar to SS14. PLoS One. 2017;12(8):e0182768

2. Gao $K$, Shen $X$, Lin $Y$, Zhu XZ, Lin LR, Tong ML, Xiao Y, Zhang HL, Liang XM, Niu JJ. Origin of Nontreponemal antibodies during Treponema pallidum infection: evidence from a rabbit model. J Infect Dis. 2018;218:835-43.

3. Lin LR, Gao ZX, Lin Y, Zhu XZ, Liu W, Liu D, Gao K, Tong ML, Zhang HL, Liu LL. Akt, mTOR and NF-kB pathway activation in Treponema pallidum stimulates M1 macrophages. Int Immunopharmacol. 2018;59:181-6.

4. Lin LR, Xiao Y, Liu W, Chen YY, Zhu XZ, Gao ZX, Gao K, Tong ML, Zhang HL, Li SL. Development of tissue inflammation accompanied by NLRP3 inflammasome activation in rabbits infected with Treponema pallidum strain Nichols. BMC Infect Dis. 2018;18(1):101.

5. Kim JH, Sohn HJ, Yoo JK, Kang H, Seong GS, Chwae YJ, Kim K, Park S, Shin HJ. NLRP3 Inflammasome activation in THP-1 target cells triggered by pathogenic Naegleria fowleri. Infect Immun. 2016;84(9):2422-8.

6. Bas S, James RW, Gabay C: Serum lipoproteins attenuate macrophage activation and toll-like receptor stimulation by bacterial lipoproteins. BMC Immunol 2010, 11(1):1-14.

7. Leemans JC, Cassel SL, Sutterwala FS. Sensing damage by the NLRP3 inflammasome. Immunol Rev. 2011;243(1):152-62.

8. Peng K, Liu LS, Wei DH, Lv YC, Wang G, Xiong WH, Wang XQ, Altaf A, Wang LL, He $\mathrm{D}$, et al. P2X7R is involved in the progression of atherosclerosis by promoting NLRP3 inflammasome activation. Int J Mol Med. 2015;35(5):1179-88.

9. Esser N, L'Homme L, De Roover A, Kohnen L, Scheen AJ, Moutschen $M$, Piette J, Legrand-Poels S, Paquot N. Obesity phenotype is related to NLRP3 inflammasome activity and immunological profile of visceral adipose tissue. Diabetologia. 2013;56(11):2487-97.

10. de Zoete MR, Palm NW, Zhu S, Flavell RA: Inflammasomes. Cold Spring Harb Perspect Biol 2015, 6(12):a016287.

11. Kanneganti TD, Özören N, Bodymalapel M, Amer A, Park JH, Franchi L, Whitfield J, Barchet W, Colonna M, Vandenabeele P. Bacterial RNA and small antiviral compounds activate caspase-1 through cryopyrin/ Nalp3. Nature. 2006;440(7081):233.

12. S M DSW, K N JM, K OR MR, WP L, Y W DMM, VM D. Cryopyrin activates the inflammasome in response to toxins and ATP. Nature. 2006;440(7081):228.

13. Hise AG, Tomalka J, Ganesan S, Patel K, Hall BA, Brown GD, Fitzgerald KA. An essential role for the NLRP3 Inflammasome in host defense against the human fungal pathogen Candida albicans. Cell Host Microbe. 2009;5(5):487-97.

14. Shio MT, Eisenbarth SC, Savaria M, Vinet AF, Bellemare MJ, Harder KW, Sutterwala FS, Bohle DS, Descoteaux A, Flavell RA, et al. Malarial hemozoin activates the NLRP3 inflammasome through Lyn and Syk kinases. PLoS Pathog. 2009;5(8):e1000559.

15. Jin C, Flavell RA. Molecular mechanism of NLRP3 inflammasome activation. J Clin Immunol. 2010;30(5):628-31.

16. Bako P, Mako A, Keglevich G, Kubinyi M, Pal K. Production of tumor necrosis factor alpha by Treponema pallidum, Borrelia burgdorferi $s$. L., and Leptospira interrogans in isolated rat Kupffer cells. FEMS Immunol Med Microbiol. 2004;40(3):187-91.

17. Babolin C, Amedei A, Ozolins D, Zilevica A, D'Elios MM, de Bernard M. TpF1 from Treponema pallidum activates Inflammasome and promotes the development of regulatory T cells. J Immunol. 2011; 187(3):1377-84. 
18. Baker-Zander S, Sell S. A histopathologic and immunologic study of the course of syphilis in the experimentally infected rabbit. Demonstration of long-lasting cellular immunity. Am J Pathol. 1980;101(2):387-414.

19. Sell S, Gamboa D, Bakerzander SA, Lukehart SA, Miller JN. Host response to Treponema pallidum in intradermally-infected rabbits: evidence for persistence of infection at local and distant sites. J Invest Dermatol. 1980; 75(6):470-5.

20. Lukehart SA, Miller JN. Demonstration of the in vitro phagocytosis of Treponema pallidum by rabbit peritoneal macrophages. J Immunol. 1978; 121(5):2014-24.

21. Goldmann T, Tay TL, Prinz M. Love and death: microglia, NLRP3 and the Alzheimer's brain. Cell Res. 2013;23(5):595-6.

22. Jourdan T, Godlewski G, Cinar R, Bertola A, Szanda G, Liu J, Tam J, Han T, Mukhopadhyay B, Skarulis MC. Activation of the NIrp3 inflammasome in infiltrating macrophages by endocannabinoids mediates beta cell loss in type 2 diabetes. Nat Med. 2013;19(9):1132-40.

23. Kanneganti TD, Lamkanfi M. K+ drops tilt the NLRP3 Inflammasome. Immunity. 2013;38(6):1085-8.

24. Muñozplanillo R, Kuffa P, Martínezcolón G, Smith BL, Rajendiran TM, Núñez G. K+ efflux is the common trigger of NLRP3 inflammasome activation by bacterial toxins and particulate matter. Immunity. 2013;38(6):1142-53.

25. He Y, Hara H, Núñez G. Mechanism and regulation of NLRP3 Inflammasome activation. Trends Biochem Sci. 2016;41(12):1012.

Ready to submit your research? Choose BMC and benefit from:

- fast, convenient online submission

- thorough peer review by experienced researchers in your field

- rapid publication on acceptance

- support for research data, including large and complex data types

- gold Open Access which fosters wider collaboration and increased citations

- maximum visibility for your research: over $100 \mathrm{M}$ website views per year

At $\mathrm{BMC}$, research is always in progress.

Learn more biomedcentral.com/submissions 